\title{
Spermatogonial morphology and kinetics during testis development in mice: a high-resolution light microscopy approach
}

\author{
Ana Luiza Drumond, Marvin L Meistrich ${ }^{1}$ and Hélio Chiarini-Garcia \\ Laboratory of Structural Biology and Reproduction, Department of Morphology, Institute of Biological Sciences, \\ Federal University of Minas Gerais, Avenida Antônio Carlos, 6627 - Pampulha, 31.270-901 Belo Horizonte, MG, \\ Brazil and ${ }^{1}$ Department of Experimental Radiation Oncology, M.D. Anderson Cancer Center, The University of Texas, \\ Houston, Texas 77030-4095, USA \\ Correspondence should be addressed to H Chiarini-Garcia; Email: chiarini@icb.ufmg.br
}

\begin{abstract}
Despite the knowledge of spermatogonial biology in adult mice, spermatogonial development in immature animals has not been fully characterized. Thus, the aim of this study was to evaluate the ontogeny of the morphological development of the spermatogonial lineage in $C 57 B L / 6$ mouse testis, using high-resolution light microscopy. Spermatogonial morphology, chronology, and absolute number were determined for different ages postpartum (pp). The morphology of spermatogonia in immature mice was similar to that of adult spermatogonia, although their nuclear diameter was slightly smaller. The $A_{1}$ spermatogonia were first observed on day 2 pp, and only $24 \mathrm{~h}$ later, differentiating type $A_{3}$ and $A_{4}$ spermatogonia were observed in the seminiferous cords. This result indicated a shortening of the spermatogonial phase for immature mice of about $\sim 2.5$ days when compared with adult mice and suggests that gonocytes and/or $A_{1}$ spermatogonia could directly become $A_{4}$ spermatogonia, skipping the developmental sequence of type $A$ spermatogonia. These $A_{4}$ spermatogonia are functional as they develop into type B spermatogonia by day 5 pp. At day 8 pp, while differentiation to spermatocytes begins, the $A_{\text {und }}$ spermatogonia reach their maximal numbers, which are maintained through adulthood. The various details of the spermatogonial behavior in immature normal mice described in this study can be used as a baseline for further studies under experimental or pathological conditions.

Reproduction (2011) 142 145-155
\end{abstract}

\section{Introduction}

At birth, the seminiferous cords of mammalian testes contain germ cells called gonocytes that are located in the center of the seminiferous cords and are arrested in the $\mathrm{G}_{0}$ phase of the cell cycle. In rodents, after birth, the gonocytes relocate toward the basal membrane (McGuinness \& Orth 1992) and resume proliferation, giving rise, after several steps, to the adult spermatogonial stem cell (de Rooij \& Grootegoed 1998, de Rooij \& Russell 2000). The passage from gonocytes to spermatogonial stem cells is not completely understood. Some authors described that the gonocytes generate an intermediate cell type called pre-spermatogonia (Huckins \& Clermont 1968), whereas others have shown that the gonocytes can give rise to either spermatogonial stem cells or differentiating spermatogonia (Kluin \& de Rooij 1981, Yoshida et al. 2006).

In adult mammals, primarily based on the data from rodents, the spermatogonial stem cell is known as an A single $\left(A_{s}\right)$ spermatogonium and is capable of self-renewal or differentiation (de Rooij \& Grootegoed 1998, de Rooij \& Russell 2000). Once it starts its path toward differentiation, the $A_{s}$ spermatogonia give rise, through mitosis, to two daughter cells that remain connected by intercellular bridges and are called $A$ paired $\left(A_{p r}\right)$ spermatogonia. These cells divide forming chains of spermatogonia, the $A$ aligned $\left(A_{a l}\right)$ spermatogonia, which can divide two or three times more in mice. The group formed by $A_{s}, A_{p r}$ and $A_{a l}$ is known as undifferentiated type $A$ spermatogonia $\left(A_{\text {und }}\right)$. The $A_{a l}$ spermatogonia will differentiate, with no mitotic division, to the differentiating type $A_{1}$ spermatogonia. The type $A_{1}$ spermatogonia undergo six successive mitotic divisions to yield $A_{2}, A_{3}, A_{4}$, intermediate-type (In), and type $B$ spermatogonia. The type $B$ spermatogonia will divide giving rise to spermatocytes, starting the meiotic process.

Although previous studies could not distinguish the various $A$ spermatogonial subtypes, high-resolution light microscopy was able to differentiate the spermatogonial 
types in adult mice (Chiarini-Garcia \& Russell 2001). The ability to distinguish these spermatogonial subtypes under light microscopy has made it possible to better understand details of spermatogonial biology in rodents under normal (Chiarini-Garcia et al. 2003), experimental (Nascimento et al. 2008), and genetically pathological (Russell et al. 2002, Bolden-Tiller et al. 2007) conditions. However, this new morphological approach has not been used to evaluate the early events of spermatogenesis development.

Thus, the goal of this study was to provide a thorough characterization of the morphology and developmental kinetics of the spermatogonial subtypes during testis development, using a high-resolution method, in order to characterize the ontogeny of this process. In addition to addressing specific questions in this process, such as the transition from gonocytes to spermatogonia, it was also our goal to provide a standard that could be used as a baseline for future functional and pathological studies.

\section{Results}

The body weights, body lengths (0-14 days), and testicular weights obtained from mice of different ages are shown in Table 1.

\section{Germ cell emergence and spermatogonial synchrony}

The timing of appearance of specific germ cells during ontogeny in the testes is shown in Table 2. The different types of spermatogonia are defined according to the criteria of Chiarini-Garcia \& Russell (2001) and are shown in Fig. 1 that are to be also observed in immature mice. The days of the first emergence of each germ cell type, from the gonocytes at birth up to elongated spermatids in adulthood, are presented in a semi-quantitative manner (Table 2). The morphology of the gonocytes is shown in Fig. 2 and the different

Table 1 Biometrical values from mice at different ages.

\begin{tabular}{lccr}
\hline Age & Body weight $(\mathrm{g})$ & $\begin{array}{c}\text { Snout-to-rump } \\
\text { distance }(\mathrm{mm})\end{array}$ & $\begin{array}{c}\text { Testis weight } \\
(\mathrm{mg})\end{array}$ \\
\hline 0 & $1.4 \pm 0.1$ & $31 \pm 1$ & $0.6 \pm 0.1$ \\
1 & $1.4 \pm 0.0$ & $31 \pm 1$ & $0.6 \pm 0.1$ \\
2 & $1.9 \pm 0.2$ & $34 \pm 1$ & $0.9 \pm 0.1$ \\
3 & $2.5 \pm 0.0$ & $36 \pm 1$ & $1.3 \pm 0.1$ \\
4 & $2.5 \pm 0.1$ & $37 \pm 0$ & $1.4 \pm 0.1$ \\
5 & $3.6 \pm 0.2$ & $40 \pm 1$ & $2.0 \pm 0.2$ \\
6 & $3.5 \pm 0.1$ & $43 \pm 1$ & $2.2 \pm 0.1$ \\
8 & $5.4 \pm 0.2$ & $48 \pm 1$ & $3.6 \pm 0.2$ \\
10 & $5.5 \pm 0.1$ & $50 \pm 1$ & $4.4 \pm 0.2$ \\
12 & $8.1 \pm 0.2$ & $58 \pm 1$ & $8.0 \pm 0.8$ \\
14 & $7.7 \pm 0.5$ & $59 \pm 1$ & $7.3 \pm 0.8$ \\
17 & $5.0 \pm 0.0$ & - & $10 \pm 0.3$ \\
20 & $7.7 \pm 0.4$ & - & $14 \pm 0.4$ \\
27 & $17.1 \pm 1.3$ & - & $48 \pm 2.0$ \\
37 & $20.2 \pm 0.4$ & - & $70 \pm 2.8$ \\
70 & $27.8 \pm 0.5$ & - & $104 \pm 1.9$ \\
\hline
\end{tabular}

The values are expressed as mean \pm S.E.M. subtypes are defined below. At birth and at day 1 postpartum ( $p p)$, only gonocytes were observed in seminiferous cords (Fig. 2a and b).

On the second day, $A_{\text {und }}$ and $A_{1}$ spermatogonia were first seen, and on the third and fourth days, spermatogonial types up to $A_{3}$ and possibly $A_{4}$ spermatogonia were already observed. On days 5 and 6 , all the spermatogonial types, as such $A_{\text {und }}, A_{1}, A_{2}, A_{3}, A_{4}$, In, and $\mathrm{B}$ spermatogonia were seen, although the most differentiated ones were seen with low frequency (Fig. 2c and d). The meiotic cells were seen on day 8 , when preleptotene spermatocytes were observed. At this time, it was possible to observe that the synchrony of the seminiferous epithelial stages between spermatogonia and spermatocytes as defined in the adult was already found; for example, the type $A_{2}$ spermatogonia were associated with leptotene spermatocytes (Fig. 3a). Based on the appearance of cells, we calculated that the first spermatogonial development in immature mice from $\mathrm{A}_{1}$ to $A_{3}$ and possibly $A_{4}$ spermatogonia occurred in $\sim 1$ day and from $A_{1}$ to $B$ spermatogonia in 3 days (Table 2).

The appearance of later stages of spermatocytes beyond leptotene was observed starting on day 10 pp. After formation of the tubular lumen, at 12 days $p p$ (Fig. 3b), pachytene spermatocytes were detected in low numbers for the first time in the seminiferous tubules and were frequently observed at 14 days (Fig. 3c) and were associated with type $A_{3}$ and $A_{4}$ spermatogonia. Meiotic figures were first seen at day 20 (Fig. $3 \mathrm{~d}$ ), when once again we could observe the synchrony as they were associated with type $A_{3}$ spermatogonia and early pachytene spermatocytes, as in adults.

The round spermatids were formed after day 20 and the first elongated spermatids were observed at day 27 (Fig. 3e), making it possible to identify all stages of the seminiferous epithelium by the acrosomal system. On day $37 p p$, the spermatogenic process was completely developed (Fig. 3f).

\section{Gonocyte and spermatogonial morphology}

In the seminiferous cords, the gonocytes pass through several morphological and positioning changes before they generate the type $A_{\text {und }}$ spermatogonia. We divided these cells into three morphologically distinct subtypes, namely I, II, and III, to further study their numbers and kinetics in an attempt to separate them into functionally different cells. All the gonocyte types had large nuclei, 10-12 $\mu \mathrm{m}$, and one to three nucleoli. Whereas the gonocyte subtype I had round nuclei, there was a progressive change to a slightly oval shape by gonocyte type III. The morphological features that allowed us to separate these three subtypes of gonocytes are as follows:

Gonocyte subtype I (Fig. 2a and e) contained condensed round nucleoli and a regular cytoplasmic membrane with no projections. They were usually 


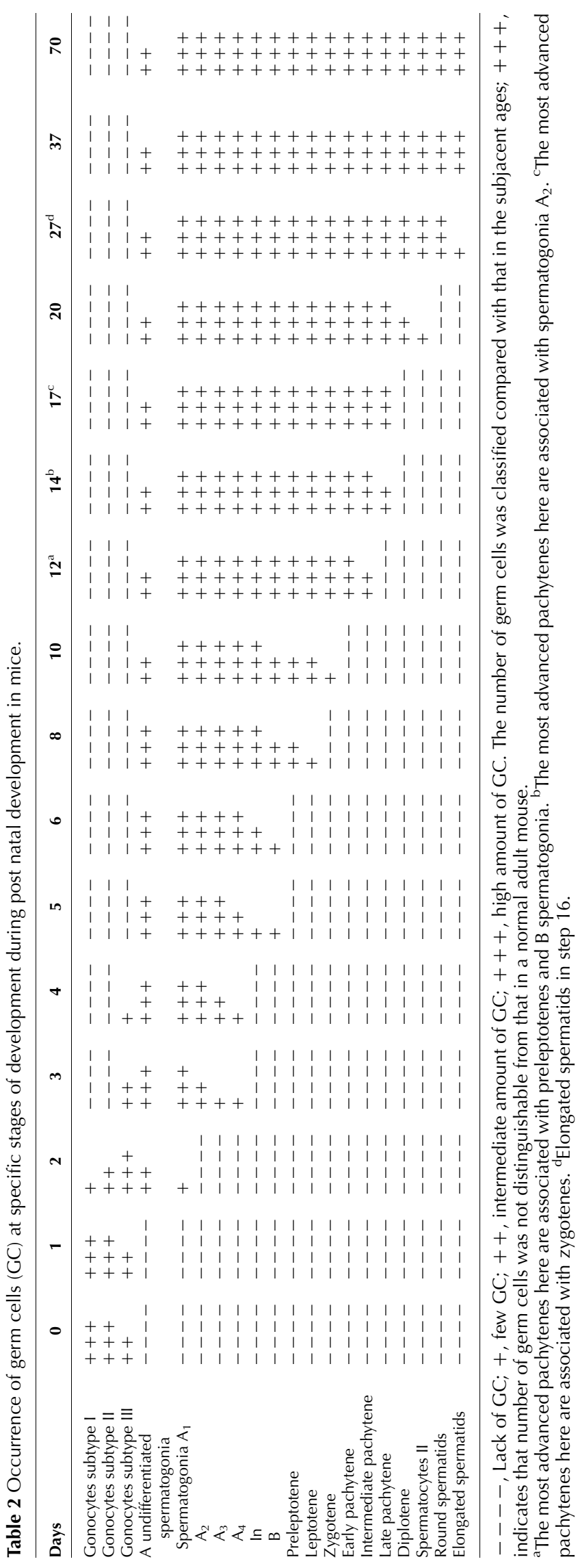

located in the center of the seminiferous cords but always separated from the basement membrane (Fig. 2a).

The nucleoli of gonocytes subtype II (Fig. 2f) were less condensed with a reticulated appearance more of an irregular shape. Although these cells were located in the center of the cords, they had cytoplasmic projections extending toward the basal membrane. These cells were frequently seen with a peculiar structure resembling acrosomal vesicles, located close to the nuclear envelope.

The nucleoli of gonocytes subtype III (Fig. 2b and g) were even less condensed and reticulated and had an irregular shape and were usually close to the nuclear envelope; spots of heterochromatin were observed, associated with the nuclear envelope; cytoplasmic membrane was irregular, but with no projections. These cells were seen lying on the basal membrane (Fig. 2b).

In contrast to the gonocytes, the $\mathrm{A}_{\text {und }}$ spermatogonia had a smaller nuclear diameter and a more oval shape, had more finely granular and darker euchromatin but lacked the spots of heterochromatin associated to the nuclear envelope of gonocytes, and the nucleoli were somewhat more condensed but more irregular. The differentiating type A spermatogonia were distinguished from the $A_{\text {und }}$ by their nuclear morphology (Fig. 1) as described in detail previously (Chiarini-Garcia \& Russell 2001), becoming larger, more lightly staining, and with increasing heterochromatin associated with the nuclear membrane. The $A_{2}$ to $A_{4}$ spermatogonia were distinguished from type III gonocytes by broader contact with the basement membrane, a more oval nuclear shape, and more irregular nucleoli.

The only noticeable differences in a given spermatogonial type, between postnatal ( 6 days) and adult (70 days) mice, were the nuclear diameters (see below). A morphologically peculiar type of A spermatogonia was observed in young animals (Fig. 1c). These cells had many of the morphological characteristics of differentiating type $A_{2}$ and $A_{3}$ spermatogonia, having an oval to round nucleus, with spots of heterochromatin around the nuclear membrane and a large, reticulated nucleolus. However, they have nuclear vacuoles, described in the literature as being located only in nuclei of type A undifferentiated cells (Chiarini-Garcia \& Russell 2001). Such nuclear vacuoles in differentiating spermatogonia were observed predominantly from 3 to 6 days $p p$, being less common in the animals that were 8 and 10 days old and were not observed in sexually mature mice.

Although this study using an accurate histological technique allowed the precise identification of almost all germ cell types during ontogenic development, the least differentiated spermatogonial type, the $A_{\text {und }}$ spermatogonia, could not be more finely sub-classified to suggest which of these cells might be stem spermatogonia. 

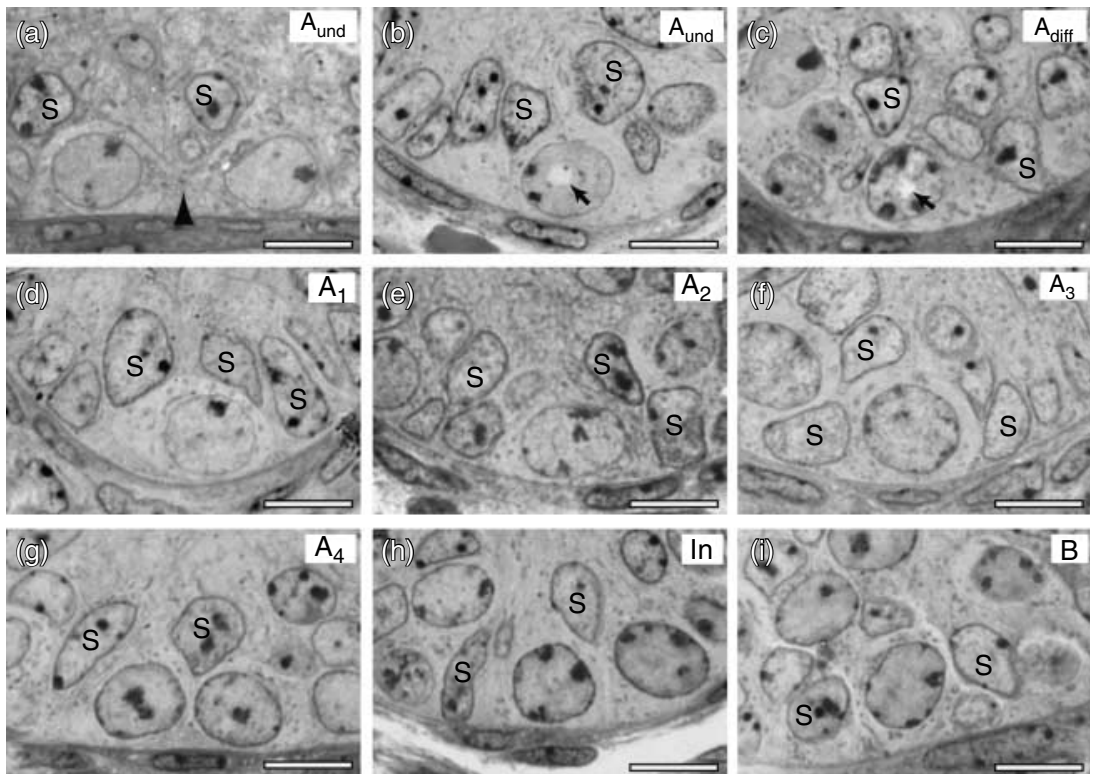

Figure 1 Spermatogonial lineage from mice at ages 2 to 6 days postpartum. (a and b) Type A undifferentiated spermatogonia, one of them with a nuclear vacuole (arrow); (c-i) differentiating spermatogonia, (c) with a nuclear vacuole (arrow), (d-g) $A_{1}$ to $A_{4}$ spermatogonia, (h) Intermediate In, and (i) B spermatogonia. S, immature Sertoli cell and arrowhead, intercellular bridge. Bars represent $10 \mu \mathrm{m}$.

\section{Spermatogonial nuclear diameter}

Figure 4 shows the average diameters of germ cell nuclei from the $A_{\text {und }}$ to type $B$ spermatogonia from 2 up to 70 days $p p$. It was observed that diameters varied during the germ cell and testes development. In all ages, the $\mathrm{A}_{\text {und }}$ spermatogonia have a smaller nuclear diameter than the differentiating type A spermatogonia. The type $\mathrm{A}_{2}$ spermatogonia were found to be the cells with the largest nuclear diameter, whereas the spermatogonia type B were the smallest (Fig. 4). The nuclear diameter of each cell type from the $A_{\text {und }}$ to In spermatogonia seemed to be larger in younger animals and decreased in size during the development, reaching their smallest nuclear diameters by 37 days $p p$.

\section{Gonocyte and spermatogonial numbers}

The changes in the total numbers of each spermatogonial type per testis during testicular development were analyzed by stereological methods. The number of gonocytes decreased progressively from birth to 3 days $p p$, whereas the numbers of differentiating type $A, I n$, and $B$ spermatogonia increased progressively up to 37 days, at puberty (Fig. 5A and B). The number of $\mathrm{A}_{\text {und }}$ spermatogonia at 8 days pp was 190000 per testis, similar to the number of type $\mathrm{A}_{\text {und }}$ spermatogonia at all subsequent ages (Fig. 5B), including the adult animals. In addition, the number of all differentiating spermatogonia reached the numbers found in the adult between 14 and 37 days pp (Fig. 5B).

\section{Gonocyte and spermatogonial kinetics}

The total number of gonocytes remained constant during the first $24 \mathrm{~h}$ after birth (Fig. 6). When the number of gonocytes of subtypes I and II went down, the number of gonocytes of subtype III increased, indicating that the former subtypes may differentiate into the latter subtype. However, it was observed that the number of gonocytes started to decline on day $2 p p$ coincident with the appearance of the first $A_{\text {und }}$ spermatogonia that start to be seen in the seminiferous cords. The decline in the total numbers of gonocytes on day 2 could possibly account for the increase in $A_{\text {und }}$ spermatogonia at that time by direct transformation of gonocytes into $A_{u n d}$ spermatogonia. However, the further increase in $A_{\text {und }}$ spermatogonia on day 3 is too large to be accounted for merely by the transformation of gonocytes and must include cell division.

\section{Gonocyte and spermatogonial mitosis and apoptosis}

The mitotic index of germ cells (gonocytes plus spermatogonia) showed an increase from birth to 3 days pp (Fig. 7), remained high until the fifth day, and then started to decrease, reaching the adult level at 10 days $p p$. The apoptotic index significantly increased after birth up to 2 days $p p$ (Fig. 7); at this time only, gonocytes were found in the seminiferous cords, pinpointing this developmental age as the time of a high number of gonocyte deaths. The apoptotic index then decreased, and already at 3 days $p p$, it reached a number as low as adult animals, remaining at this level throughout testis development.

\section{Discussion}

In this study, we have extended high-resolution light microscopy techniques to quantify the numbers of different types of gonocytes and spermatogonia cells 

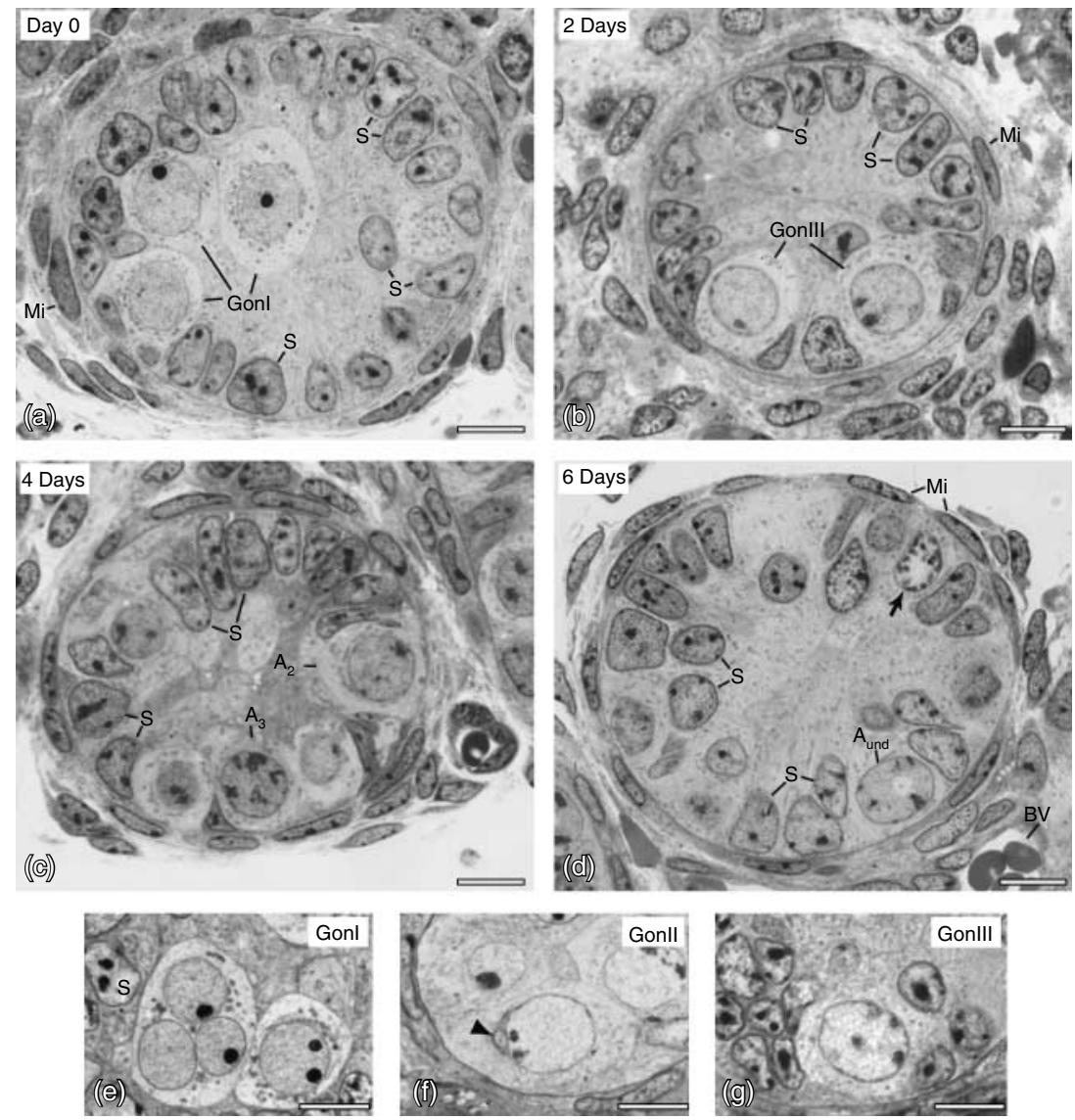

Figure 2 Seminiferous cords at day 0 (a), 2 days (b), 4 days (c), and 6 days (d) postpartum. Note the different morphological subtypes of gonocytes: gonocyte subtype I (e), gonocyte subtype II (f) with a structure close to the nuclear membrane (arrow head), and subtype III (g). Structures identified in the seminiferous cords and interstitium are labeled as follows: Sertoli cell (S), Sertoli cells in prophase (arrow), gonocyte subtype I (Gonl), subtype II (GonlI) and subtype III (GonlII), type A undifferentiated spermatogonia $\left(A_{\text {und }}\right)$, type $A_{2}$ and type $A_{3}$ differentiating spermatogonia, myoid cells $(\mathrm{Mi})$, and blood vessels (BV). Bars represent $10 \mu \mathrm{m}$. during postnatal development in the mouse. The implications of these observations for understanding the development of spermatogonia from gonocytes, the proliferation, differentiation, and kinetics of spermatogonial development and the formation of associations of the cycle of the seminiferous epithelium is discussed below.

Although we have observed different subclasses of gonocytes, which could be recognized by their morphology, number, and position in the seminiferous cords as gonocytes I, II, or III, the total number of gonocytes did not increase after birth. The mitotic index data showed that the gonocytes proliferate immediately after birth but their number did not change due to a balance between mitosis and apoptosis, which was also increased during this period. This is consistent with previous observations showing that during the first days after birth, some of the gonocytes go through mitosis (Kluin \& de Rooij 1981), but a considerable number of gonocytes degenerate (Roosen-Runge \& Leik 1968).

Kluin \& de Rooij (1981) also reported that the daughter cells of the gonocyte divisions on day 1 consist of two cell types, the typical gonocytes, called type I, and cells with larger nuclei, called type II cells. Huckins \& Clermont (1968) showed that in rats, gonocytes divide to form cells larger and lighter than the $\mathrm{A}_{\text {und }}$ spermatogonia normally found in adults and named these cells pre-A spermatogonia. Both descriptions of the gonocytes' daughter cells agree with our description for the subtype III gonocytes. As the method applied in our paper allowed better cytological distinction of the germ cells than the methods used previously, we could distinguish three gonocyte subtypes (I, II, and III) instead of two types (I and II). Kluin \& de Rooij (1981) consider the type II gonocytes to be similar to newly formed $A_{2}$ spermatogonia in adults. Our data suggest that the cells found to be type II by those authors were recognized here as subtype II and III, because the number of these cells was $67 \%$ of the total gonocytes that are very close to their percentage of type II cells (70\%). Although we agree that these gonocytes are similar to type $A_{2}$ spermatogonia, we could still morphologically recognize the spermatogonial subtypes in young mice, and it was possible to show that the gonocytes II and III are morphologically different from type $A_{2}$ spermatogonia.

The emergence of type $A_{\text {und }}$ and $A_{1}$ spermatogonia, at day 2 , morphologically similar to the those observed in adult mice, is consistent with the results of Yoshida et al. (2006), who demonstrated at 2 days $p p$ the presence of the first germ cells that expressed KIT (c-Kit) receptor in the seminiferous cords. Furthermore, they showed that 

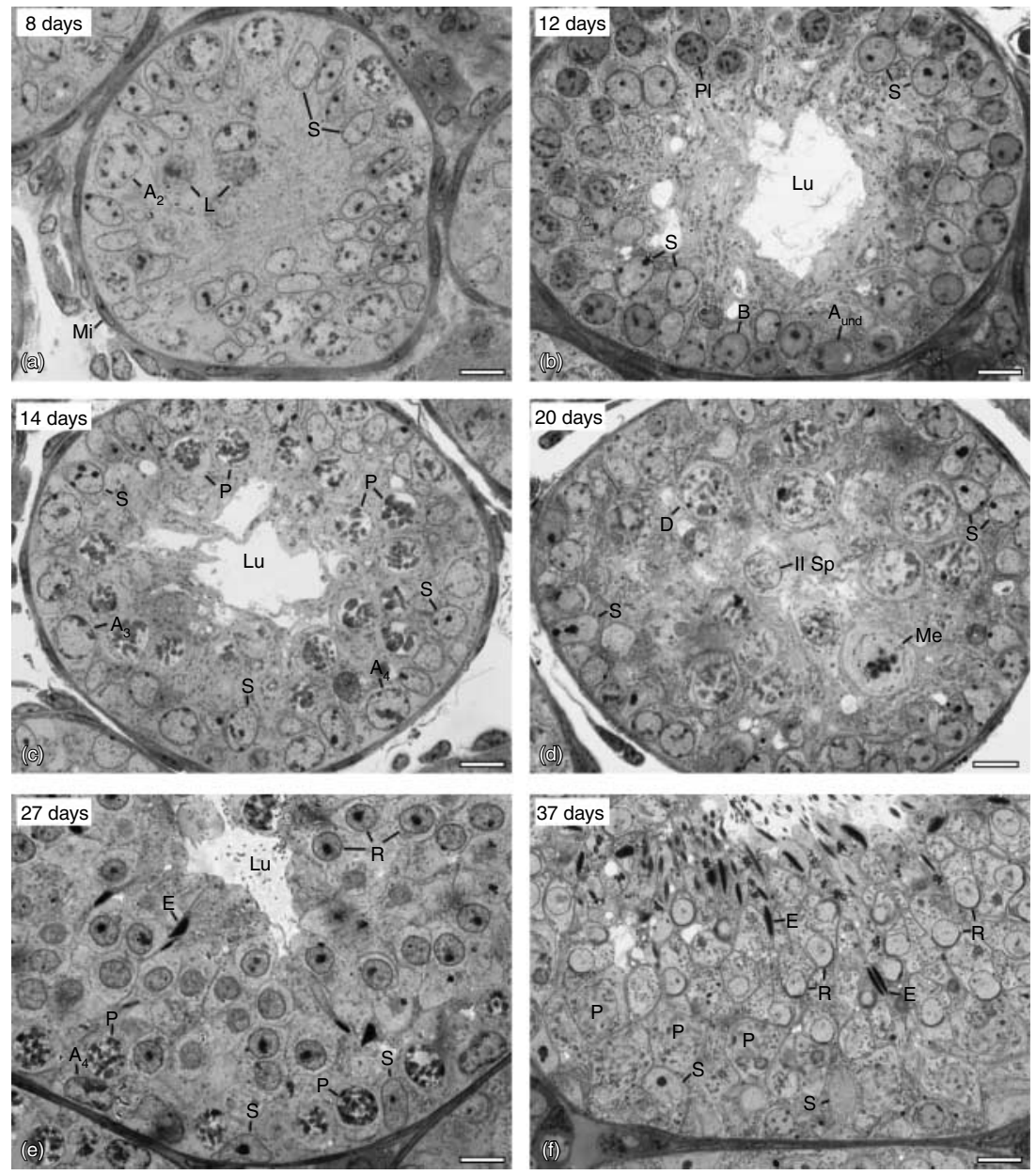

Figure 3 Seminiferous epithelium at ages of 8 days (a), 12 days (b), 14 days (c), 20 days (d), 27 days (e), and 37 days $(\mathrm{f})$ postpartum. Structures indicated are Sertoli cells $(S)$, type $A$ undifferentiated $\left(A_{\text {und }}\right)$, type $A_{2}$ differentiating spermatogonia $\left(A_{2}\right)$, type $A_{3}$ differentiating spermatogonia $\left(A_{3}\right)$, type $A_{4}$ differentiating spermatogonia $\left(A_{4}\right)$, type $B$ differentiating spermatogonia $(\mathrm{B})$, pre-leptotene $(\mathrm{Pl})$, leptotene $(\mathrm{L})$, pachytene $(\mathrm{P})$, diplotene $(\mathrm{D})$, secondary spermatocyte (II Sp), round spermatid (R), elongated spermatid (E), and lumen (Lu). Bars represent $10 \mu \mathrm{m}$. these cells must correspond to a population of germ cells that skip at least one of the molecular steps of spermatogonial differentiation that occurs in adults, because the KIT-positive cells that were rapidly formed did not express neurogenin 3 (NGN3), which is expressed in type $\mathrm{A}$ undifferentiated spermatogonia of the adult mice (Yoshida et al. 2006). This result indicates that the first type $A$ differentiating spermatogonia $\left(A_{1}\right.$ and/or $A_{2}$ spermatogonia) are part of a cell population that is directly derived from the gonocytes separately from the $A_{\text {und }}$ spermatogonia. The later development of differentiating spermatogonia, which have gone through a stage of NGN3 expression, must come from a subset of these $A_{\text {und }}$ cells, which correspond both morphologically and functionally to the adult spermatogonial stem cells.

In this study, the first type $A_{1}$ spermatogonia were seen in the seminiferous cords at 2 days $p p$, and surprisingly only $24 \mathrm{~h}$ later, spermatogonia morphologically similar to type $A_{3}$ and possibly some $A_{4}$ spermatogonia were also observed. In adult mice, three mitotic divisions are required for a differentiating spermatogonia type $A_{1}$ to become type $\mathrm{A}_{4}$ spermatogonia, and this process requires a time interval of about 3.5 days (Clermont \&
Trott 1969, de Rooij \& Russell 2000). This short time suggests that gonocytes and/or $A_{1}$ spermatogonia are directly becoming $A_{3}$ and/or $A_{4}$ spermatogonia. Although it might be argued that the $A_{3}$ and $A_{4}$ spermatogonia produced on days 3 and 4 are not functionally the same as those in the adult, they do go on to produce $B$ spermatogonia on day 5, preleptotenes on day 8 , zygotene spermatocytes on day 10 , and pachytene on day 12; thus, they are functionally acting as differentiated type A spermatogonia. The data in Table 2 can also be used to calculate that, in immature mice, the formation of $B$ spermatogonia (day $5 p p$ ) from $A_{1}$ spermatogonia (day $2 p p$ ) occurs in 3 days, whereas in adults this transition requires 6.1 days, showing that the process was shortened $\sim 3$ days, which appears to have largely been due to the acceleration of type A spermatogonial development between days 2 and 3 . Hence, our results indicate that there is acceleration of the spermatogonial phase, involving skipping generations of the developmental sequence of the type A spermatogonia that are normally observed in adults. It should be noted that in this study, the steps involved in this acceleration were only morphologically defined. The combination of immunohistochemistry 


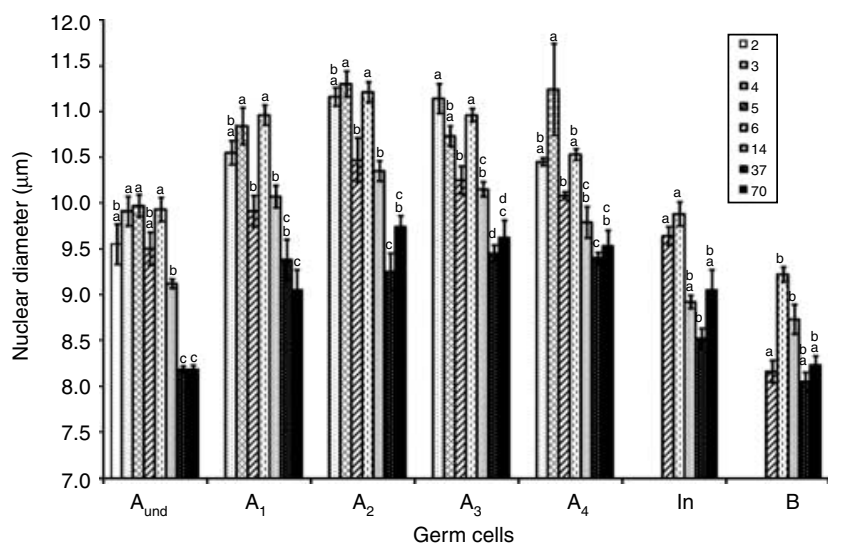

Figure 4 Nuclear diameters of spermatogonia $\left(A_{\text {und }}, A_{1}, A_{2}, A_{3}, A_{4}\right.$, In, and $\mathrm{B}$ ) in some of the analyzed ages. Values are expressed as mean \pm s.E.M. Different letters show significant differences in the nuclear diameter of the same cell type among different ages $(P<0.05)$.

for spermatogonial markers and morphology is necessary to further characterize the development in molecular terms.

Thus, our data showed that the shorter timing of the spermatogenesis in the immature C57BL6 mice was, at least partially, due to an acceleration of the spermatogonial phase. However, the faster development of spermatocytes and/or spermatids in immature $C p b-N$ mice observed by Kluin et al. (1982) was not observed in the present investigation. Possible reasons for this discrepancy could be due to the broad interval between 17 and 27 days $p p$ in our study, which may lack the resolution necessary to observe a small acceleration or differences among the strains of mice.

It is well known that spermatogenesis in adult mammals occurs in a cycle and that each differentiating germ cell in the seminiferous epithelium is always associated with specific other types of germ cells, constituting the stages of the seminiferous epithelium, which in mice can be classified into 12 different stages (Oakberg 1956, Russell et al. 1990). Although we cannot precisely stage the cross sections of the tubules through the acrosomal system before the appearance of spermatids, from 8 days $p p$, when the first primary spermatocytes can be observed, onward, the spermatogonial subtypes are associated in the same manner with the more differentiating cells following the same stage relationships as seen in adult mice. This confirms that the spermatogonial organization is already regulated, even before the Sertoli cells become mature (Vergouwen et al. 1991, Joyce et al. 1993). This observation is consistent with data showing that the genes expressed in adult Sertoli cells in a cyclical manner are already expressed in young immature Sertoli cells (Timmons et al. 2002).

It is useful to relate the data obtained here on the number of $A_{u n d}$ spermatogonia to the stem cell potential in transplantation experiments. Although it was generally believed that the $A_{s}$ spermatogonia within the $A_{\text {und }}$ population contain the stem cells (de Rooij \& Russell 2000), recent data indicate that the $A_{p r}$ and $A_{a l}$ spermatogonia can also occasionally undergo clone fragmentation and normally have a low potential to be stem cells (Nakagawa et al. 2010). However, their potential for producing stem cells is increased when these cells are used for spermatogonial transplantation (Nakagawa et al. 2007). Thus it is reasonable to consider the total numbers of $A_{\text {und }}$ spermatogonia as at least a crude measure of the stem cell potential in transplantation experiments.

It is interesting to note that 8-day-old animals, although being quite young, have the same total number of type $A_{\text {und }}$ spermatogonia in the whole testis as do adult animals. Most spermatogonial transplantation experiments use young animals as donors of germ cells (Shinohara et al. 2001, McLean et al. 2003), finding that 12-day-old mice seem to be the best donors. McLean et al. (2003) found that the germ cells of these animals produced a higher number of colonies in the recipient testes than those from 1 to 5 days $p p$ mice, consistent with the present observation of a greater number of $A_{\text {und }}$ spermatogonia in the 12-day-old mice. The observation that 10- or 12-day-old mice were more efficient at
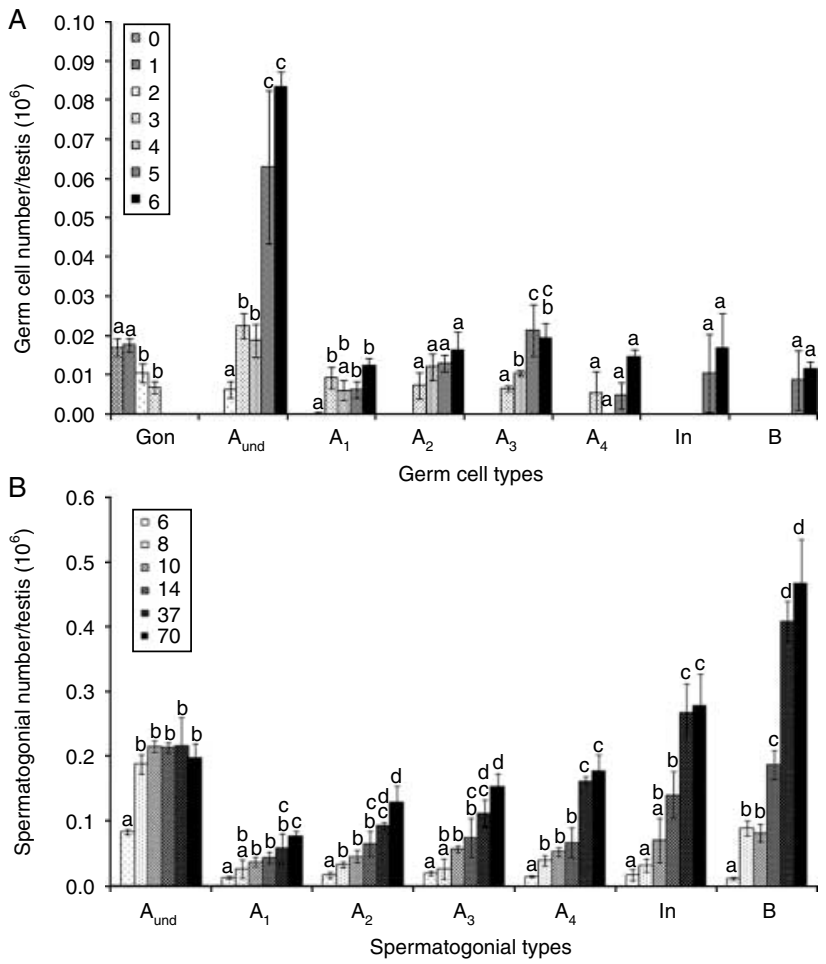

Figure 5 Total number of gonocytes and spermatogonia per testis from 0 to 6 days postpartum (A) and at 6, 8, 10, 14, 37, and 70 days postpartum (B). Values expressed as mean \pm s.E.M. Different letters represent significant differences between different ages for each cell type analyzed $(P<0.05)$. 


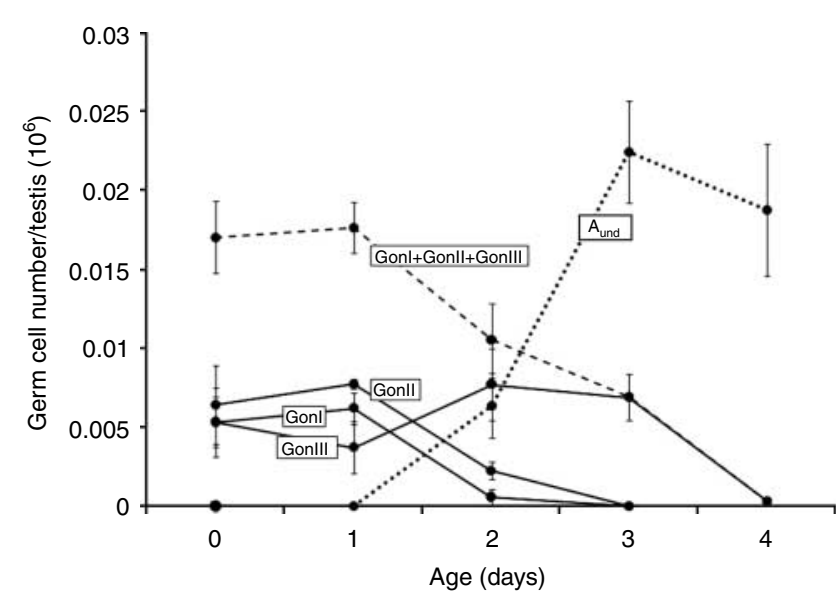

Figure 6 Total number of gonocytes (Gonl, Gonll, and GonlII) and type $A$ undifferentiated spermatogonia $\left(A_{u n d}\right)$ per testis from 0 to 4 days postpartum. Values expressed as mean \pm s.E.M.

colonizing recipient testes (McLean et al. 2003) is consistent with the observation in this study, that the number of type $A_{\text {und }}$ spermatogonia in 10- to 12-day-old mice is between 30 and 50 million/g testis, whereas the number of $A_{u n d}$ spermatogonia in the adult mice is 1.9 million/g (Fig. 5 and Table 1).

In conclusion, our data showed, for the first time, that animals at 8 days $p p$ have maximal numbers of type $A_{\text {und }}$ spermatogonia in the testis parenchyma and higher concentrations of these cells when compared with adult mice. Furthermore, the data confirm that the spermatogenic cell differentiation occurs faster in young animals than in adults, by skipping multiple divisions of differentiating type A spermatogonia resulting in a shortening of $\sim 2.5$ days in the spermatogonial phase. Overall, the capacity to identify the different spermatogonial subtypes by their morphological characteristics in a normal ontogenetic process could be used as a tool to better understand spermatogonial biology during early postnatal development and provide a simple and reliable method to evaluate spermatogonial development in immature life under adverse circumstances, such as experimental or pathological conditions.

\section{Materials and Methods}

\section{Animals and histological procedures}

Testes from mice of the C57BL/6 strain at 0, 1, 2, 3, 4, 5, 6, 8, $10,12,14,17,20,28,37$, and 70 days $p p$ were collected (day 0 was birth date). We used four mice per group. Mating pairs were randomly provided by Federal University of Minas Gerais mouse colony and were bred by investigators. Pups for each age group were generally chosen for the different groups from different litters. This study was previously approved by the ethics committee in Animal Experimentation from the Federal University of Minas Gerais.
After measurement of body weight, mice were anesthetized with sodium pentobarbital ( $30 \mathrm{mg} / \mathrm{kg}$ body weight) via i.p. injection and testes were fixed by immersion or perfusion. Animals from 0 to 14 days of age had their testis removed, weighed, and fixed by immersion in $5 \%$ glutaraldehyde (biological grade; EMS, Hatfield, PA, USA) and in $0.05 \mathrm{M}$ cacodylate buffer ( $\mathrm{pH}$ 7.4). After an initial fixation for $30 \mathrm{~min}$, the tunica albuginea was removed and the fixation period was extended for $24 \mathrm{~h}$ more at $4{ }^{\circ} \mathrm{C}$. The testes were cut into thin slabs of $\sim 1 \mathrm{~mm}$ thickness and kept in the same buffer, at $4{ }^{\circ} \mathrm{C}$, until embedding. Animals older than 17 days of age were fixed by perfusion via the cardiac route as described previously (Chiarini-Garcia \& Meistrich 2008). Heparin was injected i.p. (130 U/100 g body weight) $15 \mathrm{~min}$ before anesthesia. After that, saline was initially perfused to clear the blood from testis, followed by $5 \%(\mathrm{v} / \mathrm{v})$ glutaraldehyde in a $0.05 \mathrm{M}$ cacodylate buffer ( $\mathrm{pH}$ 7.4). Then, the right and the left testes were removed and sliced transversely into small slabs that were also kept in $0.05 \mathrm{M}$ cacodylate buffer, at $4{ }^{\circ} \mathrm{C}$, until embedding. Fragments of both testes, randomly chosen from all mice, were post-fixed in a $1 \%(\mathrm{w} / \mathrm{v})$ osmium tetroxide and $1.25 \%(\mathrm{w} / \mathrm{v})$ potassium ferrocyanide mixture, dehydrated in a graded series of ethanol, infiltrated, and embedded in Araldite 502 (EMS). Sections ( $1 \mu \mathrm{m}$ thick) were obtained from the resin blocks and were stained with toluidine blue-borate for high-resolution light microscopic studies.

\section{Morphological analysis}

The main goals of the morphological evaluations of the gonocytes and spermatogonia during testis development were 1) to identify the cellular features, comparing them with those described in adult mice by Chiarini-Garcia \& Russell (2001), 2) to identify the most advanced germ cell type at each age evaluated, and 3) to determine whether spermatogonia from type $A_{1}$ spermatogonia up to type $B$ spermatogonia have the same strict associations as those described in adult animals regarding the seminiferous epithelial cycle. Cellular characterization was based on nuclear features such as shape of the

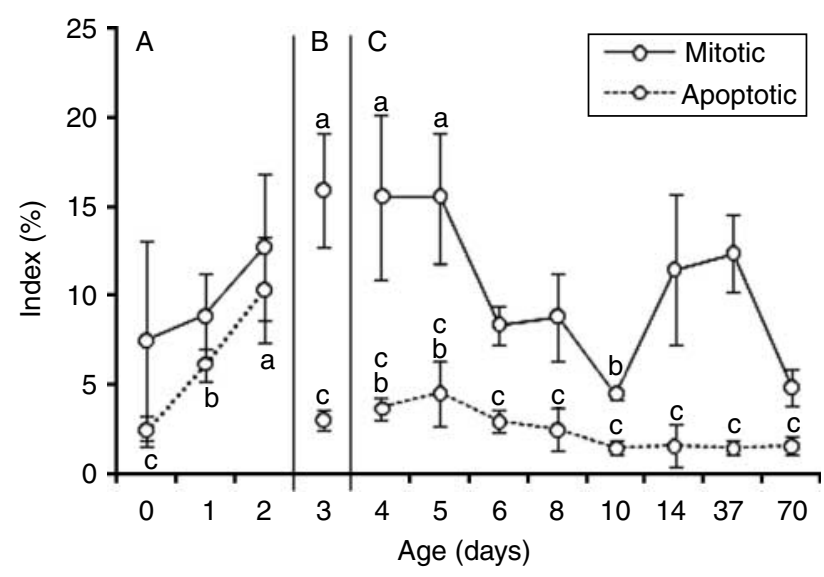

Figure 7 Mitotic and apoptotic indexes of gonocytes (A), gonocytes mixed with spermatogonia (B), and spermatogonia (C), during testis development. Values expressed as mean \pm S.E.M. Different letters represent significant difference between different ages $(P<0.05)$. 
nucleus, presence, and arrangement of heterochromatin, granularity of euchromatin, and morphology and degree of nucleolar compaction.

\section{Morphometrical procedures}

Morphometrical studies were performed to obtain the absolute number of different subtypes of gonocytes and different spermatogonial types $\left(A_{\text {und }}, A_{1}, A_{2}, A_{3}, A_{4}, I n, B\right)$ per testis for all ages studied. For this purpose, the following parameters were obtained:

volume of testicular parenchyma $-V_{\mathrm{T}}\left(\mu \mathrm{m}^{3}\right)$

volume density of seminiferous epithelium $-V v_{\mathrm{e}}$ absolute volume of seminiferous epithelium $-V t_{\mathrm{e}}\left(\mu \mathrm{m}^{3}\right)$

nuclear volume density of each spermatogonial subtype $-V v_{n}$ absolute total nuclear volume of each spermatogonial subtype $-V t_{\mathrm{n}}\left(\mu \mathrm{m}^{3}\right)$

nuclear volume of each spermatogonial subtype $-V n\left(\mu m^{3}\right)$ cellular number/testis - CN $\left(10^{6}\right)$.

The weight of testicular parenchyma is the testis weight without the tunica albuginea weight. As the testicular density is $\sim 1 \mathrm{~g} / \mathrm{ml}$ (1.03-1.04; Sinha-Hikim et al. 1988), each gram of testis corresponds to a volume of $10^{12} \mu \mathrm{m}^{3}$. Hence, $V_{T}$ is obtained multiplying the testicular parenchyma weight $(\mathrm{g})$ by $10^{12} \mu \mathrm{m}^{3}$.

The volume density of the seminiferous epithelium was estimated using the point counting method (Sinha-Hikim et al. 1988, Russell et al. 2002). These data were obtained through an Olympus BX-41 light microscope with a $40 \times$ objective and using a square lattice containing 441 intersections in a $10 \times$ eyepiece. We counted $\sim 4410$ intersections on the seminiferous epithelium and the rest of testicular parenchyma, distributed in ten randomly selected fields per animal (two to three fields per histological section), for each age studied. The volume density of seminiferous epithelium $\left(V v_{\mathrm{e}}\right)$ was obtained dividing the sum of the points falling on seminiferous epithelium by the total number of points over the tissue. The volume of seminiferous epithelium $\left(V t_{\mathrm{e}}\right)$ was estimated as follows:

$V t_{\mathrm{e}}=V_{\mathrm{T}} \times V v_{\mathrm{e}}$

The nuclear volume density of gonocytes and each spermatogonial subtype was also estimated using point counting, applying the same 441 square lattice with a $100 \times$ objective. In 40 randomly selected fields for each animal (four to five fields per histological section), the intersections over the nuclei of each cell type were recorded. The nuclear volume density of each spermatogonial subtype $\left(V v_{n}\right)$ was obtained by dividing the sum of the points falling on each cell subtype by the total points over the seminiferous epithelium. The total volume of each germ cell subtype $\left(V t_{n}\right)$ was estimated as follows:

$V t_{\mathrm{n}}=V t_{\mathrm{e}} \times V v_{\mathrm{n}}$.

To calculate the nuclear spermatogonial volumes $(V \mathrm{n})$, it is necessary to first determine the nuclear diameter $(D)$. The diameter of ten nuclei of each germ cell subtype was measured for each animal, using a ruler fitted in a $10 \times$ eyepiece, calibrated with a micrometer ruler. For each spermatogonial cell type, the nuclei that appeared to have the largest profiles were selected to be measured, because that indicates that the sections were close to the center of the nucleus. The volume was calculated as:

$V_{n}=\frac{\pi D^{3}}{6}$.

After the determination of the total volume of each germ cell subtype $\left(V t_{n}\right)$ and the spermatogonial nuclear volumes $(V n)$, it was possible to calculate the absolute cell number $(\mathrm{CN})$, in millions $\left(10^{6}\right)$, for each spermatogonial type per testis as follows:

$$
\mathrm{CN}=\frac{V t_{\mathrm{n}}}{V n} \text {. }
$$

\section{Mitotic and apoptotic indexes of gonocytes and spermatogonia}

To calculate the mitotic and apoptotic indexes, the following components of the seminiferous epithelium were counted: a) the number of gonocytes and spermatogonia, b) the number of mitoses, and c) the number of apoptotic gonocytes and spermatogonia. Approximately 30 tubular cross sections were
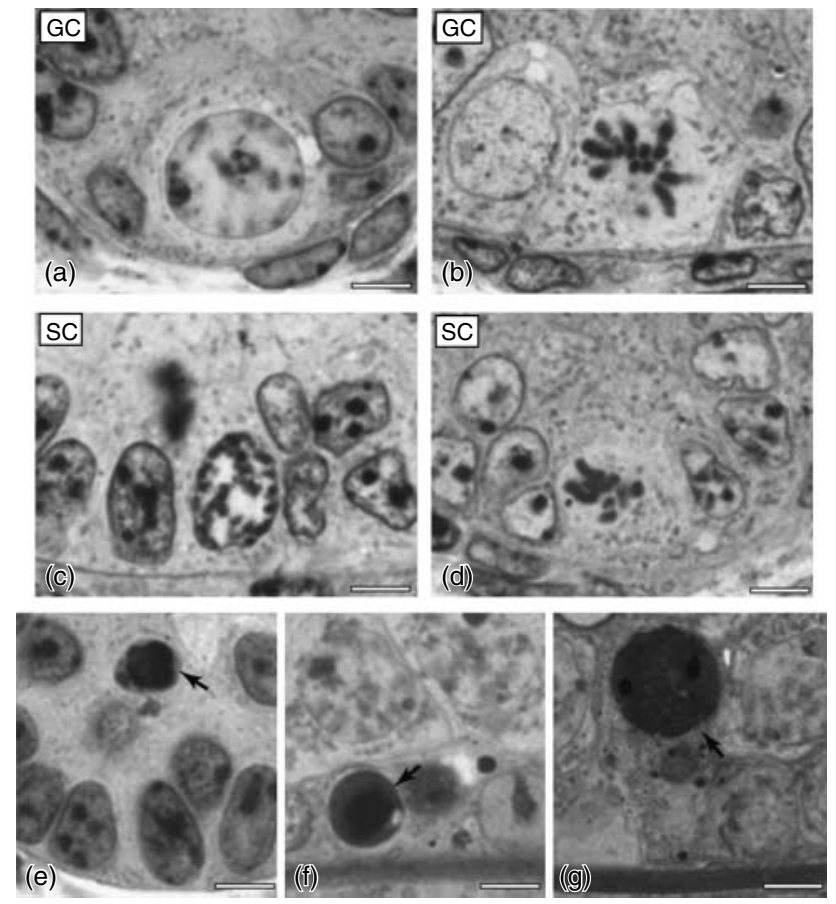

Figure 8 Morphological features of mitotic phases of germ and Sertoli cells in neonatal testes: panels (a) and (c) represent prophase, and panels (b) and (d) represent metaphase. GC, germ cells (a and b) and SC, Sertoli cells (c and d). Morphological features of apoptotic germ cells: panel (e) represents a seminiferous cord at 3 days $p p$, with an apoptotic gonocyte in the center (arrow), panel (f) represents an apoptotic spermatogonium (arrow), located close to the basal membrane, and panel (g) represents apoptotic spermatocyte (arrow). Bars represent $5 \mu \mathrm{m}$. 
counted per animal. The mitotic and apoptotic indexes were calculated by dividing the number of mitoses and/or apoptotic cells, respectively, by the sum of gonocytes, spermatogonia, mitoses, and apoptosis.

Specific criteria were needed to distinguish the mitotic spermatogonia from mitotic Sertoli cells. In prophase, the two cell types were clearly distinguished, as they still have the nuclear characteristics of the cells in interphase (Fig. 8a and c), whereas in other mitotic phases, the mitotic spermatogonia were distinguished from mitotic Sertoli cells by their cytoplasmic features. The mitotic figures of germ cells were identified by the outline of their cytoplasmic membrane, separating their cytoplasm from the Sertoli cells' cytoplasm, and by the density of their cytoplasm, which was brighter than the Sertoli cells (Fig. 8b). The Sertoli cells in mitosis usually displayed no cytoplasmic membrane delimitation, or an elongated outline, with processes toward the center of the cords/tubules, and their cytoplasmic density was more homogenous with the cytoplasm around it (Fig. 8d).

The identities of the cells that produced the apoptotic bodies were morphologically determined according to the border blebbing and fragmentation of the chromatin (Fig. 8e, $\mathrm{f}$, and $\mathrm{g}$ ). When the cytoplasm is observed, the following features are considered: a) its shape (elongated in spermatogonia and round in spermatocytes), b) whether it is contacting basal lamina (spermatogonia are in contact with the basal lamina) and c) how it is contacting (flattened in spermatogonia or punctuated in spermatocytes). The nuclei have particular characteristics that enable their assignment to different cell types such as a) shape, b) size, c) position in the cytoplasm, d) granularity of chromosome fragmentation, finely granular in spermatogonia (Fig. 8f) and coarsely granular in spermatocytes (Fig. 8g), e) number of joined apoptosis (normally spermatogonia are alone), and f) the stage of the epithelium cycle where the spermatocytes are larger and usually far from the basal lamina.

\section{Statistical analysis}

The morphometrical data were expressed as mean \pm S.E.M. Groups were compared using ANOVA, followed by Fisher's LSD and Turkey's tests when necessary. The results were considered to be statistically significant if $P<0.05$. All analyses were performed using SPSS 15.0 software (SPSS, Inc., Chicago, IL, USA).

\section{Declaration of interest}

The authors declare that there is no conflict of interest that could be perceived as prejudicing the impartiality of the research reported.

\section{Funding}

This study was supported in part by the following Brazilian Foundations: Coordenação de Aperfeiçoamento de Pessoal de Nível Superior (CAPES), Fundação de Amparo à Pesquisa do Estado de Minas Gerais (FAPEMIG), and Conselho Nacional de Pesquisa (CNPq).

\section{Acknowledgements}

We thank Maria Luiza da Silva and Adriano Moreira Ferreira for assistance in histological preparation.

\section{References}

Bolden-Tiller OU, Chiarini-Garcia H, Poirier C, Alves-Freitas D, Weng CC, Shetty G \& Meistrich ML 2007 Genetic factors contributing to defective spermatogonial differentiation in juvenile spermatogonial depletion (Utp14b/jsd) mice. Biology of Reproduction 77 237-246. (doi:10. 1095/biolreprod.107.060087)

Chiarini-Garcia H \& Meistrich ML 2008 High resolution light microscopic characterization of spermatogonia. Methods in Molecular Biology 450 95-107. (doi:10.1095/biolreprod65.4.1170)

Chiarini-Garcia H \& Russell LD 2001 High resolution light microscopic characterization of mouse spermatogonia. Biology of Reproduction 65 1170-1178. (doi:10.1095/biolreprod65.4.1170)

Chiarini-Garcia H, Raymer AM \& Russell LD 2003 Non-random distribution of spermatogonia in rats: evidence of niches in the seminiferous tubules. Reproduction 126 669-680. (doi:10.1530/rep.0. 1260669)

Clermont Y \& Trott M 1969 Duration of the cycle of the seminiferous epithelium in the mouse and hamster determined by means of ${ }^{3} \mathrm{H}$-thimidine and radioautography. Fertility and Sterility 20 805-817.

Huckins C \& Clermont Y 1968 Evolution of gonocytes in the rat testis during late embryonic and post-natal life. Archives d'Anatomie, $d^{\prime}$ Histologie et d'Embryologie 51 343-354.

Joyce KL, Porcelli J \& Cooke P 1993 Neonatal goitrogen treatment increases adult testis size and sperm production in the mouse. Journal of Andrology 14 448-455.

Kluin PM \& de Rooij DG 1981 A comparison between the morphology and cell kinetics of gonocyte and adult type undifferentiated spermatogonia in the mouse. International Journal of Andrology 4 475-493. (doi:10. 1111/j.1365-2605.1981.tb00732.x)

Kluin PM, Kramer MF \& de Rooij DG 1982 Spermatogenesis in the immature mouse proceeds faster than in the adult. International Journal of Andrology 5 282-294. (doi:10.1111/j.1365-2605.1982. tb00257.x)

McGuinness MP \& Orth JM 1992 Reinitiation of gonocytes mitosis and movement of gonocytes to the basement membrane in testes of newborn rats in vivo and in vitro. Anatomical Records 233 527-537. (doi:10.1002/ ar.1092330406)

McLean DJ, Friel PJ, Johnston DS \& Griswold MD 2003 Characterization of spermatogonial stem cell maturation and differentiation in neonatal mice. Biology of Reproduction 69 2085-2091. (doi:10.1095/biolreprod. 103.017020)

Nakagawa T, Nabeshima Y \& Yoshida S 2007 Functional identification of the actual and potential stem cell compartments in mouse spermatogenesis. Developmental Cell 12 195-206. (doi:10.1016/j.devcel.2007. 01.002)

Nakagawa T, Sharma M, Nabeshima Y, Braun RE \& Yoshida S 2010 Functional hierarchy reversibility within the murine spermatogenic stem cell compartment. Science 328 62-67. (doi:10.1126/science. 1182868)

Nascimento HF, Drumond AL, França LR \& Chiarini-Garcia H 2008 Spermatogonial morphology, kinetics and niches in hamsters exposed to short- and long-photoperiod. International Journal of Andrology 32 486-497. (doi:10.1111/j.1365-2605.2008.00884.x)

Oakberg EF 1956 A description of spermiogenesis in the mouse and its use in analysis of the cycle of the seminiferous epithelium and germ cell renewal. American Journal of Anatomy 99 391-414. (doi:10.1002/aja. 1000990303)

de Rooij DG \& Grootegoed JA 1998 Spermatogonial stem cell. Current Opinion in Cell Biology 10 694-701. (doi:10.1016/S0955-0674(98) 80109-9)

de Rooij DG \& Russell LD 2000 All you wanted to know about spermatogonia but were afraid to ask. Journal of Andrology 21 776-798. 
Roosen-Runge EC \& Leik J 1968 Gonocyte degeneration in the postnatal male rat. The American Journal of Anatomy 122 275-299. (doi:10.1002/ aja.1001220208)

Russell LD, Ettlin RA, Sinha Hikim AP \& Clegg ED 1990 Histological and Histopathological Evaluation of the Testis, edn 1. Vienna, IL: Cache River Press.

Russell LD, Chiarini-Garcia H, Korsmeyer SJ \& Knudson CM 2002 Bax dependent spermatogonia apoptosis is required for testicular development and spermatogenesis. Biology of Reproduction 66 950-958. (doi:10.1095/biolreprod66.4.950)

Shinohara T, Orwing KE, Avarbock MR \& Brinster RL 2001 Remodeling of the postnatal mouse testis is accompanied by dramatic changes in stem cell number and niche accessibility. PNAS 98 6186-6191. (doi:10.1073/ pnas.111158198)

Sinha-Hikim AP, Bartke A \& Russell LD 1988 Morphometric studies on hamster testes in gonadally active and inactive states: light microscope findings. Biology of Reproduction 39 1225-1237. (doi:10.1095/biolreprod39.5.1225)
Timmons PM, Rigby PW \& Poirirer F 2002 The murine seminiferous epithelial cycle is pre-figured in the Sertoli cells of the embryonic testis. Development 129 635-647.

Vergouwen RPFA, Jacobs SGP, Huiskamp R, Davids JAG \& de Rooij DG 1991 Proliferative activity of gonocytes, Sertoli cells and interstitial cells during testicular development in mice. Journal of Reproduction and Fertility 93 233-243. (doi:10.1530/jrf.0.0930233)

Yoshida S, Sukeno M, Nakagawa T, Ohbo K, Nagamatsu G, Suda T \& Nabeshima Y 2006 The first round of mouse spermatogenesis is a distinctive program that lacks the self-renewing spermatogonia stage. Development 133 1495-1505. (doi:10.1242/dev.02316)

Received 19 October 2010

First decision 9 December 2010

Revised manuscript received 25 February 2011

Accepted 26 April 2011 